\title{
Techniques used to Improve Spatial Visualization Skills of Students in Engineering Graphics Course: A Survey
}

\author{
Asmaa Saeed Alqahtani \\ Department of Computer Science \\ Najran University \\ Najran, Saudi Arabia
}

\author{
Lamya Foaud Daghestani \\ Department of Computer Science \\ King Abdulaziz University \\ Jeddah, Saudi Arabia
}

\author{
Lamiaa Fattouh Ibrahim \\ Department of Computer Science \\ King Abdulaziz University \\ Jeddah, Saudi Arabia
}

\begin{abstract}
Spatial visualization skills are crucial in engineering fields and are required to support the spatial abilities of engineering students. Instructors in engineering colleges indicated that freshmen students faced difficulties when visualizing models in engineering graphics. Students cannot correctly understand and process visual object and mental images of the engineering models. Traditional tools using textbooks, physical models, and modeling techniques is not sufficient for improving the spatial visualization skills of engineering students. This paper is a survey of all techniques used to learn freshmen students in engineering graphics and improve their spatial visualization skills. Also, it presents the method of evaluation the spatial visualization skills. After describing techniques and presented the literature review, this work presents a comparison between methodologies and techniques used in previous studies. Finally, we summarize a road of the map for the techniques and strategies to improve the spatial visualization skills for freshmen engineering students.
\end{abstract}

Keywords-3D graphics; virtual reality; spatial visualization skills; mental rotation skill; engineering graphics

\section{INTRODUCTION}

The most important skill in engineering fields is Spatial Visualization Skills (SVS) [1]. SVS defined as "the ability to generate, retain, retrieve and transform well-structured visual images" [2]. Spatial ability is the ability of the human brain to produce, keep, retrieve, and transform the 3D models, virtual images, and objects. Spatial ability related to the cognitive load of memory. If students improve their spatial skills, then there is no overloaded in the cognitive load [3].

To improve SVS, we need to improve Mental Rotation Skill (MRS) [4]. MRS is the ability to mentally transform 3D objects and virtual images by rotating it in the space (in mind). MRS need a cognitive process to allow a person to mentally (in space) transform by rotating 3D objects and virtual images [2]. MRS is classified of a type of spatial skills. Most of the studies conduct that the spatial skills are essential for the engineering students. Such as, in [1] conducts that the spatial visualization is related to the engineering fields, MRS is related to SVS to build 3D models, and the spatial skill is required for the computer graphics in engineering [1].

Instructors in engineering colleges lock solving the difficulties faced the freshmen students in studying engineering graphics course when they tried to visualize the models [5]. Students cannot easily understand and processing the visual objects and mental images [6]. Traditional tools using textbooks, physical models, and modeling techniques is not enough to graduate engineering students with high SVS, and they fail to pass the graphic courses with high grade [7].

The freshmen engineering students need to have high MRS and ability to mentally visualize the 3D models like it in reality [7]. The MRS improved by training students to use virtual models and interacting with it by using their eyes and hands [8], [9]. The training before studying the courses will allow students to improve their MRS and then study better with a little of difficulties. Engineering students also need to improve their SVS, and hence improving the working of the memory of human brain. Improving the working memory leads to high cognitive load in the brain [9].

The next section discusses strategies of MRS. Section 3 represents the techniques used to improve SVS and MRS. After that, Section 4 discusses the methods of evaluation SVS and MRS. Section 5, the literature review. Section 6 compares the papers worked in the field of enhancing the SVS. Section 7 the adaptation systems. Section 8 represents the gender differences in MRS. Section 9 summarize the road map of this survey. The paper's conclusion presented in section 10 .

\section{Strategies FOR LEARNING MENTAL Rotation SKILL}

There are three strategies for learning MRS in a 3D environment. The three cognitive styles are a holistic mental rotation, analytical mental rotation, and the combination of two previous strategies that called combined strategy [10].

\section{A. Holistic mental rotation}

The holistic mental rotation is rotating a 3D object mentally without considering for any features of the object such as color, coordinate axes, shadow, and size [10]. The holistic mental rotation is rotated for a $3 \mathrm{D}$ object without any steps for rotating it. The males are tending to use the holistic mental rotation and solving the mental rotation tests using this style by using the right hemisphere which is responsible for the holistic mental rotation [10]. Parallel style "tend to encode visual images globally as a single perceptual unit, which they process holistically" [11]. 


\section{B. The analytical mental rotation}

The analytical strategy based on rotating the object mentally step by step. The features of objects are considered to rotate the object mentally. The analytical mental rotation is used by females to solve the spatial visualization tests and tend to use the left hemisphere which is responsible for the analytical mental rotation [10]. Sequential style "tend to encode and process images analytically, part by part, using spatial relations to arrange and analyze the components" [11].

\section{Combined mental rotation}

The third type of mental rotation cognitive styles is a combined of holistic and analytic styles. The combined style allows learners to rotate a 3D object mentally by both the left and right hemispheres when rotating the object mentally. In this style, the user can mentally rotate the object with holistic processing and analytical processing based on some features of the object. The later studies by Li [12], [13], [14], [10], [15] noticed and concluded that the females are tending and preferring to use the combined strategy or analytical strategy.

\section{TECHNIQUES USED TO IMPROVE SPATIAL VISUALIZATION SKILLS}

The following sections describe the different techniques used to improve SVS.

\section{A. Software tutorials}

There were two electronic tutorials used for first-year students in engineering college to teach the engineering subjects in electronic methods rather than just based on textbooks. The two tutorials are Visual Reasoning Tutorial and Orthographic Projection Tutor. The Visual Reasoning Tutorial allows students to construct a solid model from two orthographic projections. The Visual Reasoning Tutorial has a glass box with the model inside it. The students need sweeping operations to construct that model [16].

\section{B. Flash courseware}

Flash courseware is an electronic course that allows interactive $3 \mathrm{D}$ elements to add in an electronic course designed by Flash with text and images. It constructed by using ActionScript and library of Sandy to build 3D elements animated using Flash [17].

\section{E-Learning module}

There is a developed E-Learning module based on "Computer Aided Interactive Learning of Engineering Graphics." This module aimed to utilize the computer abilities for computing the attributes of the geometric model such as plans, sections of solids, and perspective projections. It consists of many pages and exercises as it a traditional book, but it presented on a computer screen with a little of animation by the degree of angles for 2D orthographic and planes [18].

\section{EBook, multi-touch screen technology}

Electronic book or e-book is a digital tablet. The digital tablet produced by many companies and brand such as Windows, Apple, and Samsung. The digital tablet contains operating systems such as iOS or Android systems. These ebooks (digital tablets) has multi-touch screen features. It allows the user to touch screen as it a smartphone. There are applications on it used to educate engineering students and improve their SVS [19].

\section{E. Virtual reality}

The virtual reality (VR) is a newly emerging computer interface characterized by high degrees of immersion, believability, and interaction, with the goal of making the user believe, that he is actually within the computer-generated environment [9]. According to [20], VR is " technology that allows us to create environments where we can interact with any object in real time, and that has been widely used for training and learning purposes." Integration some of the technologies, such as computer and graphics, can generate the technology of the VR. So, the VR can outline as it is a progressing computer interface to allow the person to be immersed within a simulated environment generated by a computer.

\section{F. Augmented reality}

Augmented Reality (AR) is one type of VR according to the feeling of immersion. The different types of the VR systems take place according to different using of technological supplies. Those various suppliers represented in various displayed hardware and interaction devices. "Virtual reality systems are classified according to the level of immersion they provide, ranging from semi-immersive virtual reality to fully immersive virtual reality to augmented reality (AR)" [9].

The non-immersive system often called desktop VR (without any input devices). It is based on the monitor screens as it is a window to the virtual world without an additional device. The AR is one type of the VR systems.

\section{G. Portable document format}

Portable document format 3D (PDF3D) is PDF format embedded 3D models. The PDF3D can read the 3D models. The 3D models embedded in PDF can manipulate by the user [21].

\section{H. Web3D}

The Web3D is the web contain 3D models as it VR and AR environments. The web3D designed using software such as AutoCAD, 3D website (browsers), X3DOM, Maya, 3D Studio, and Blender. Also, it can use a programming language to create $3 \mathrm{D}$ models such as virtual reality modeling language (VRML) [22].

\section{The SketchUp software}

The SketchUp produced by Trimble used to build a system allows students to put a paper contained 3D model designed by SketchUp in front of the camera, then the model constructed as it in reality. This system has a plugin such as AR [23].

\section{J. Colored 3D models:}

The Coloured 3D models used instead of monochrome models. It is a $3 \mathrm{D}$ printed model on paper and presented on a computer screen as static 3D models. The user wears blue glasses to see the shadow of 3D models on the screen of computer [24]. 


\section{K. Training website:}

Training website contained 3D standard models based on holistic mental rotation strategy. The website contained many levels [7].

\section{Evaluation Methods of Spatial Visualization SKILLS}

A standard test of SVS is needed for each student before and after applying proposed techniques to measure improvement and enhancement of their SVS. There are many measures to test the MRS. The measures (standard tests) are Mental Rotations Test (MRT), Purdue Spatial Visualization Test (PSVT), Purdue Spatial Visualization Test: Rotations (PSVT: R), Online surveys, and Concurrent STEM course grades [25], [26].

The basic test is MRT. It founded in 1971 by Shepard and Metzler. A mental rotation test is a measurement tool for MRS and SVS. However, it used for general STEM fields. MRT is the most test has difficulties in calculating the result of students when they tested to measure their improved mental rotation. MRT required to calculate not result of the test, but also how much response time for each question with calculating error rate [27], [26].

One of the standard tests is special for academic using and the engineering field. The test is PSVT: R. We are going to use this test in our research. The PSVT: R is exceedingly used in different fields and programs of engineering in colleges and universities. The PSVT: $R$ used in engineering learning and education because it based on isometric drawings for spatial visualization [2]. Moreover, PSVT: $\mathrm{R}$ used in engineering colleges because it "can be used as an assessment tool for diagnosing and improving students' spatial visualization skills in any engineering course that requires basic understandings of visual representation of objects" [28].

PSVT: R considered MRT, but it is developed in 1977 by Bonder and Guay with more facilities. MRT considered at most of the rotation skill only and all questions of the test based on ten cubes face-to-face as it is a rigid arm-like structure as shown in Fig. 1. The student decided if two objects are matched or dis-matched, or can choose one of three models which one rotated as the original model [29]. Moreover, the samples of questions are not available and need to use a computer to test it due to the needing to calculate the response time. However, PSVT: R consider both rotation and spatial skill with visualization ability.

The PSVT test consists of three parts that are "development" to see how the student can visualize the folding of 3D objects. The second part is "rotation" to see how the student can mentally rotate the 3D objects. The third part is "visualization" to see how the student can visualize 3D objects from on point view through glass cube [29]. The PSVT test is suitable for a student from 15 age and older especially the engineering students. The following Fig. 2, 3, and 4 show the PSVT test examples.
Fig. 2 shows the first part of PSVT that is development test. One object is not folding and just drown in 2D. Then the student needs to fold and visualize the structure of 3D objects. After that, the student selects one answer among five answers. In the example of Fig. 2, the correct answer is only B. Each part consists of 12 questions.

Fig. 3 shows the second part of PSVT: R that is rotation test. One object rotated in particular directions. The original and rotated 3D objects shown as an example for the student. Then another 3D object is displayed and ask the student to rotate it mentally as in the direction of example, and then select only one rotated $3 \mathrm{D}$ object among five answers. The correct answer in this example is only D.

Fig. 4 shows the third part of PSVT that is view test. A 3D object is drawn and asks the student to imagine it as in a glass cube, and he/she is around the cube. Then, the student has to move around the cube until he/she see the black dot between student and 3D object. After that, the student visualizes the structure of the subject matter according to his seeing of an object in the direction of the black dot. Select one answer among five 3D objects. The correct answer in the example of Fig. 4 is the only E.

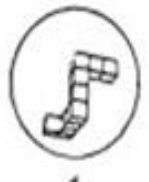

1.

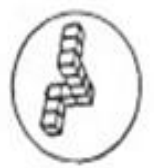

2.

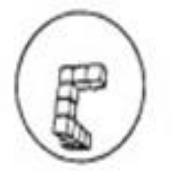

A



A

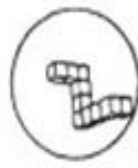

B

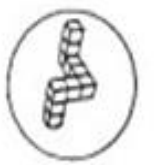

B



C



C
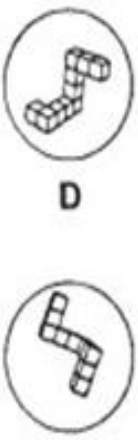

D
Fig. 1. Sample problem MRT


E.

Fig. 2. PSVT test (development part), [30] 


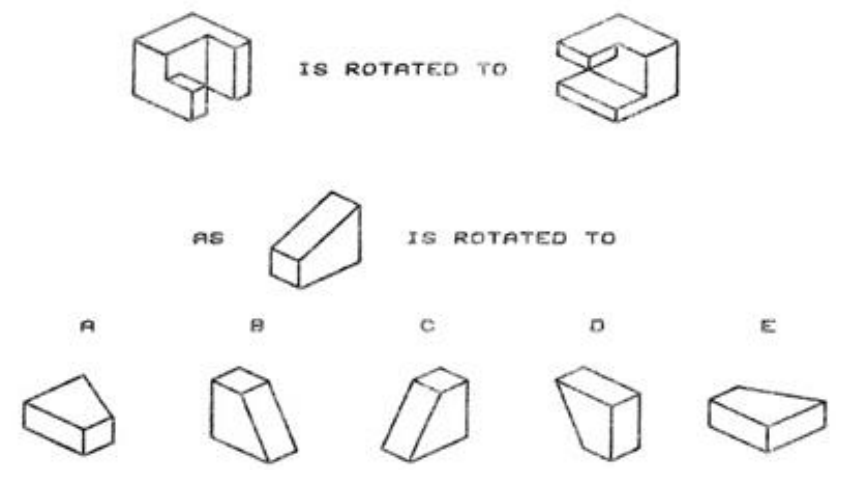

Fig. 3. PSVT:R test (rotation part), [30]

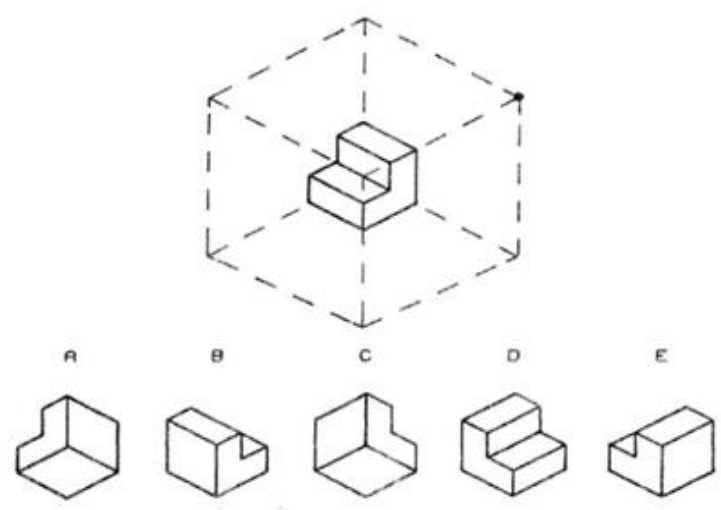

Fig. 4. PSVT test (view part), [30]

The part of the rotation is as shown in Fig. 3 that is PSVT: $R$. It is considered one of the standard tests of mental rotation [31]. In general, PSTV there are 36 questions, with 6 questions answered before all three parts ( 2 answered question as examples for each part).

In the PSVT: R, There are 30 questions with solving examples and the students have to answer it during 20 minutes by Guay in (1976) [28]. The PSVT: R available in the ETS test collection and has since been widely used by researchers in engineering and technology fields.

In 2009, before release the Revised PSVT: R, Smith [32] suggests adding the axes of coordinates to the questions of PSVT: R. Adding the axes is to represent the orientation of objects in space to minimize the effect of spatial visualization in the exam. Moreover, adding the coordinates is to because the students take twenty minutes to solve twenty question whether it thirty questions as Barnoff concluded in his research [27]. An example for PSVT: R with axes shows in Fig. 5.

\section{Literature ReVIEW}

In this section, we present the previous studies used to facilitate the education of engineering students and improve their SVS and MRS. All the following studies used one or many of techniques, mental rotation strategies, a method of evaluations mentioned in section 3 and 4.

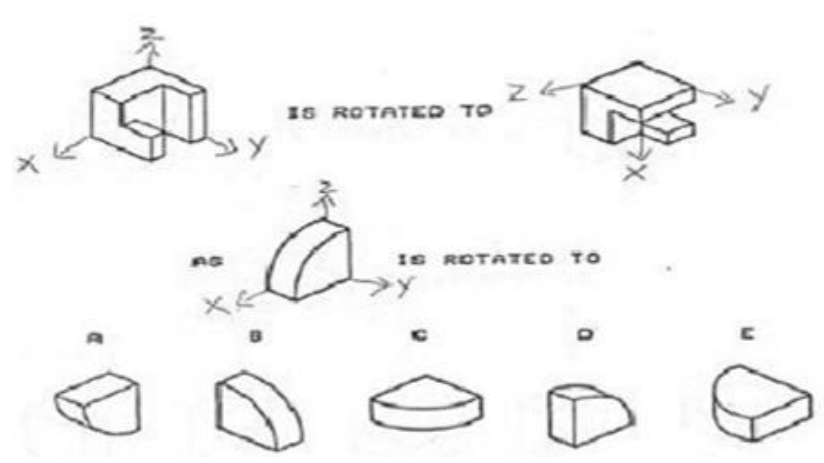

Fig. 5. Sample of PSVT: R with labels for axes

Esparragoza in [16], proposed to use two tutorials in many effective tools for the freshman students in Engineering College to teach and learn the engineering subjects in better methods rather than just based on textbooks. The two software tutorials are Visual Reasoning Tutorial and Orthographic Projection Tutor.

Visual Reasoning Tutorial allows students to construct a solid model from two orthographic projections. The Visual Reasoning Tutorial has a glass box with the model inside it. The students need sweeping operations to construct that model.

The first tutorial is Visual Reasoning Tutorial consist of many missing view problems to help students to complete the process of visual thinking and visual analysis. There is more than one solution possible for the same problem. The students can check their solutions by using assistant constructed in this tutorial. There are many sweeping operations in this tutorial with edges forming the face of a solid model. The students can have direct feedback after each sweeping and constructing operations.

The second tutorial is Orthographic Projection Tutor. It is a software also designed for the freshman engineering students to start solving problems at the highest level. Each problem in this tutorial has many exercises about the concepts of orthographic projections. The Orthographic Projection Tutor made the concepts and issues related and linked based on the definitions and concepts in orthographic projection by using a learning network.

The using of physical models in engineering graphics replaced in this research by those two tutorials Visual Reasoning Tutorial and Orthographic Projection Tutor.

The tutorials constructed by using AutoCAD and SolidWorks software to enhance the visualization skills of 3D presented in engineering graphs for the students.

On the other hand, the developed module was not enough to improve the visualization skills in engineering graphics. The proposed E-Learning module was like traditional books contain pictures and texts.

Manseur in [33], discussed the concepts of the VR and using of its tools in science in general and especially in 
engineering education to encourage the using of visualization. The author presented software tools with many examples of using and developing the VR in sciences and engineering. The VRML discussed in this research with many languages that can integrate with it. To develop the using of VRML, new software tools integrated into a graphical programming language such as Visual C++, Visual Basic, Java, Labview or other. These tools with programming language have Graphical User Interface (GUI) to allow the students to interact with the VR model.

In engineering education, the usage of $3 \mathrm{D}$ visualization will enhance the teaching and learning of excellent modeling and simulation methods. Spazz3D is one programming software package that used effectively by integrating it with VRML. It has GUI to seek the input from students and introduce the result in efficient methods.

Using of VRML will assist the students to understand the six degrees of 3D space with a mathematical representation of a solid model. A small program called POS and RPY Animator created. The program allows the students to choose a solid model, entering the position and the value of orientation, and then having the virtual displays of the model. The students can move the object into its corresponding location.

Using VRML with graphical programming language allows the animation of 3D objects either by the user action or automatically. The animation in VRML will support the visualization of moving systems.

However, the program created in this research is just reflecting the vectors and the orientation of the 3D model in space. It lacks for the real visualization for the plans and the orthographic projection of a model.

In [17], Hong and Mie proposed a new method to allow interactive 3D elements to be added in Flash courseware. The authors construct this method by using ActionScript and library of Sandy and construct a 3D view of Sandy APIs and Flash functions management. The using of the new method implemented with engineering graphics courseware.

The proposed method applied to engineering graphics. The example presented to show the teaching of the intersection curve using Flash courseware and to how the intersection curve will be when the two cylinders intersect. It allows students to translate the solid object in $\mathrm{x}, \mathrm{y}$, and $\mathrm{Z}$-axes by using the keyboard. Also, it allows students to rotate the camera around the axis.

This research presented a method to add interactive 3D elements into Flash courseware. SandyAPIs used to create the view of a $3 \mathrm{D}$ object in space. However, the proposed method needs to support to visualize the objects as real. It did not present the plans and projections of objects. Students still need to see, understand, and realize the model in space using VR.

In [19], Torre et al. proposed a functional prototype of the interactive multi-touch eBook with built-in digital capabilities drawing aimed at engineering graphics and visualization courses. The prototype targeted to enhance the concepts of engineering graphics and concepts of visualizations. The proposed multi-touch book consists of many exercises, textual elements, and rich media content to allow students to digitally sketching in the electronic environment like the traditional environments that include paper, pencil, and eraser.

The proposed prototype combines both eBook and interactive multi-touch screen features. The multi-touch digital book allows students to visualize and interact 3D models contained in the eBook. The concepts are about orthographic projections and multi-view drawing. It included interactive sketching exercises. The study applied to iPad only using Apple's iBooks. The prototype in a tablet is as widgets. The students can draw automatically on the screen as its real paper, and submit the solved exercises to the instructors immediately using e-mail. The widget that proposed consisted of many elements such as photo gallery, sketching environment, 3D models, and many exercises, videos to learn about covering orthographic, projection and multi-view drawings, and email to allow students to send exercises and assignments to the instructors and to get the feedback.

To evaluate the proposed prototype, a comparative study made between two groups of students. The first group study using traditional tools, while the second group studies the course in one semester using the eBook multi-touch screen. Also, the authors made questionnaire about the prototype. The results showed positive reaction and approval.

On the other hand, the prototype specified for iPad from Apple's Company only. The students need to see and visualize the models as it in the real world with visual height and width to rotate its plans by students themselves as its touchable models.

In [21], Martin et al. aimed to develop educational material based on AR formats and several virtual. The authors also proposed to recognize how students behave while using teaching materials based on AR formats and several virtual, and checking if they are useful materials to improve their spatial skills and capabilities.

The work presented three different technologies that are AR, VR, and PDF3D. The three techniques applied to three groups of students in the same classroom and the same level. One of these technologies applied to all three groups and then studied to find out the spatial ability progress of the student, and discovering the impact of the tool used in the acquisition of graphic design knowledge. There is a fourth group (control group) that will not use any of three technologies. They will use the traditional methodology of teaching and learn the concepts and models in engineering graphics that based on the textbook and real models only.

The AR technology uses either direct or indirect view of a physical environment of the real world and uses a set of devices to combine virtual information and material information that already exists. This study uses distinct AR from VR. The exercise in this material based on AR constructed using BuildAR Pro AR application. BuildAR Pro AR allows to create scenes consists of the set of images or marks that modify a 3D object. After creating the scene, a webcam on the computer recognizes an image that related to the 3D model and showed it integrated into the real world.

The portable document format included in PRO-X version. This material has many features that are an open standard, 
multiplatform, extendable, reliable and secure, sophistication for information integrity, search capability, accessibility, and interactive.

All three technologies have the same goal that the student gets to know the piece instead of a real physical model and allow the student to get the information needed to sketch the piece and create a workshop contour plan.

The authors present a pilot study to compare the results of improvement in spatial ability need for freshman engineering students. The research also showed a survey about satisfaction and motivation of the proposed methodology using the three technologies. The study did in the graphic design laboratory.

Based on the results of motivations using a survey, the students reached a good level of development in the learning the visual skills. However, the students made inappropriate use of the strategies of the proposed technologies. They still need to the existence of instructor to guide them.

Another study used AR technique by Gutierrez [34] suggested another solution using mobile augmented reality (MAR) instead of using desktop VR by AR. Gutierrez and his colleagues designed an application called DiedricAR based on MAR. The application aimed to use for descriptive geometry which based on (graphical language engineering).

The application designed to support the autonomously and ubiquitous learning. The DiedricAR system used by students to learn how to solve dihedral exercises (drawing exercises) and showing 3D models based on its 2D orthographic in the workbook (augmented book). The workbook is the traditional book contains exercises and pages, but with the possibility to capture the exercise statement and showing it a solution with 3D models on the screen of smart devices.

The DiedericAR consists of a workbook, models, and markers. The models are 3D models displayed on the screen of smart devices based on the orthographic projection exercises in the book.

The system of smart devices applied to the DiedrcAR application Android and iOS. However, the system tested only on Android system that is "Samsung Galaxy Tab 10.1; Samsung Galaxy SII; Samsung GT-P- 1000; Samsung Galaxy Ace; LG Optimus L3; Samsung Galaxy 3 GT i-5800”.

The DiedricAR system used by 20 students selected randomly. This group of a student called group B, while another group (group A) was not using the system. The Gropu A take the course with traditional materials only.

Two mental tests used for both groups that are: PSVT: R and Differential Aptitude Test (DAT-5: SR): spatial visualization. Also, a questionnaire introduced to group B to assess them satisfy about the DiedricAR system. The grade of tests shows that group B improved by $17 \%$ more than another group (group A).

On the other hand, the system still needs to support the tactile module. The students need to visualize the 3D models and their orthographic projection in virtual space as it is in the real world. The using of smart devices required using the camera and the textbook. Moreover, there are no need to use the handle drawing nowadays; especially we live in the technologies and technical world.

Another research study in 2015 by Gutierreza et al. [35] aimed to create an AR based on the didactic content of engineering graphics course. The AR application was instead of traditional material such as traditional textbook, using paper and pencil, and modeling using SketchUp software, and online multimedia web-based exercises.

The designing of AR application constructed by using AR, USB Camera (QuickCam Pro 9000), AR-Dehaes, and computer vision techniques. The AR application has many levels and exercises in the AR book.

The AR application has software that displays 3D models on a computer screen by capturing it from the paper of the book. By capturing the model, it's constructed as it 3D model on a computer screen. Moreover, the levels of AR application have videos to explain the orthographic concepts and freehand sketching. The notebook of exercises contained on AR application. The exercises such as find wrong in 2D orthographic views, draw one view of orthographic projections based on existing two views of the same model and draw 3D models (perspective) based on the orthographic projections.

The AR application designed for engineering students at the La Uaguna University in Spain.

The experiment applied to the training group of students. The students tested two tests that are (DAT-5: SR Level 2) and (MRT). Also, the researchers introduce a survey for the students to evaluate the AR application (usability and satisfaction). The results of mental tests and questionnaire conclude that the training students have high marks and their spatial ability improved through the training system.

On the other hand, the system focus on training the students how to draw $3 \mathrm{D}$ perspective with its projection views, while there are a lot of computer programs can do it easily and with less effort and time of works. Likewise, the students cannot scan and view the 3D models as it in real by rotating, translate, flying and zooming. The students still need to learn from the tactile model of learning (by the

In [7], the study used VR and one strategy of mental rotation strategies. This study used holistic mental rotation for both genders. That is, there is no any features for the 3D models. The rotation of 3D models was based on choosing a number of angels. It was website training contained many levels.

The software and tools used for building the website were HTML, SQL database, Amazon server, and JavaScript. The hardware were laptops and desktop computers.

The evaluation of this study used Revised PSVT: R test. The outcomes of this study were improving in students score of PSVT: $\mathrm{R}$ test. The "increase for males in the experimental group was 1.72 times greater than that of the comparison group (experimental group $(\mathrm{N}=75)$, and the comparison group $(\mathrm{N}=134)$ )" and "The increase for females in the experimental group was 2.45 times greater than that of the comparison group. (experimental group $(\mathrm{N}=19)$, and the comparison group $(\mathrm{N}=29))$ '. 
On the other hand, the strategy of this training is supporting for the males more than females. The 3D models rotated in axes directions only and based on precise angles degree. The researcher used all models of PSVT: $\mathrm{R}$ in training. It should be two sets of models (training sets and testing sets).

Another study to solve the problem of spatial visualization in engineering graphics is done by Olmedoa et al. [22] in 2015. Olmedoa and his colleagues assumed the necessary of interacting with $3 \mathrm{D}$ models to obtain good results. Olmedoa suggested building web3D for university-level students. To build web3D, the researchers aimed to use VR/AR, and they implemented it.

The web3D contains many 3D models. It designed by many software and tools such as CAD, VRML, Catia, 3D website (browsers), X3DOM, Maya, 3D Studio, and Blender to form web3D for engineering students. By those tools, the researchers built VR/AR environment. Many universities connect to this web3D such as the University of the Basque Country. It allows students to interact the models by rotating it and moving it only without zooming the models.

The web3D system (AR/VR system) used with other traditional techniques used in education, such as Blackboard, PowerPoint presentation, and textbooks. The system is used only in the labs of universities.

After using the web3D by students, a survey introduced about the advantages and disadvantages of VR system based on web3D. The results were as the following:

- $70 \%$ and more of the students agreed with the advantages of the web3D system. It has improved the student's spatial ability rather than imagining a 3D model when it's constant (printed) on paper.

- $70 \%$ and more were asking to have the system on their personal laptops and PCs, and in classrooms, not only in labs through university's connections.

- $50 \%$ of students was not agreed. They have opined that the system has disadvantages because the system does not offer permanently and not installed on their personal computers. They need to use and practice it at home. Moreover, they take the time to wait for the connection between university and web3D.

- Also, the $50 \%$ students complain that the models cannot zoom for more viewing and scanning.

Katsioloudis et al. in [24], published research in 2016 about how to develop the spatial ability of engineering students using the impact of colored 3D models (by using colored 3D models). They assumed based on past researches that the information has color will improve the cognitive load and help students to get more information without losing it easily. So, the researchers suggest using colored 3D models instead of monochrome models (black or white models). However, the using of more color will negative effect spatial ability and cognitive load.

This study aimed to use colored 3D models for three control groups of students that are: the first group used 3D printed model without color. The second group used the same printed 3D models, but also wearing blue glasses. The third group used PC contains 3D blue models with its shadow on the screen.

The spatial visualization ability was measured using two data collection instruments that are MCT (MindConsciousness-Thought) and the creation of section view drawing. Then the results analyzed using ANOVA to find the mean and significant differences for each group.

The results and the average of each group are very similar without significant differences. The researchers after concluding that there are no differences assumed that the spatial ability would improve only for students who have low ability. Moreover, the researchers believe that "the population used (engineering technology students) did not demonstrate a statistically significant difference in spatial abilities from the addition of the color because spatial skills were well developed in this population" [24].

On the other hand, the research lacked to use the VR to create models and allow students to visualize it, rotate it, and scan the models as in the real. There is a need to add a third channel of learning that is (tactile module) by using the hands. The previous research was based only on the visual module (using eyes only). There is a need to use all three channels of learning based on the VR model for Cognitive learning [9]. We assumed to use that model with affecting of brightness and shadow of color 3D models.

Another prominent researcher is Sorby. She has been doing many types of research since 1999 till 2016 to improve the SVS of engineering students and comparing between the females' and males' skills when they are doing the mental rotation tests. In her researches [36], [37], [1], [38], [39], she was trying to change the content of engineering courses. Also, changing the methods of teaching and using the modeling programs such as CAD programs to improve the SVS of students. The researcher did not yet introduce a training system specific for improving the MRS and independent of the contents of the course. However, the researcher concluded that there is a difference in MRS depends on the gender.

\section{COMPARISON BETWEEN ALL PAPERS WORKED IN THE FIELD OF ENHANCING SVS}

This section compares all previous studies based on many criteria such as if the paper used technique based on any strategy of MRS, whether paper used random 3D models or models from exercises of course or standard models used in measurement tools as PSVT. Moreover, the comparison shows whether paper proposed system as it course or system training, and what gender targeted for its study.

We can see in Table 1 that only one paper used mental rotation strategy. The black box means that paper satisfies the property. However, it was the holistic mental rotation and this strategy not suitable for females. In the second column, no paper based on any adaptation system to make the training fit for every student's level and skill of learning. In the next section, we present more detail about the adaptation systems. 
TABLE I. COMPARISON BETWEEN PAPERS PRESENTED IN LITERATURE REVIEW

\begin{tabular}{|c|c|c|c|c|c|c|c|c|c|}
\hline \multirow{2}{*}{ Ref. } & \multirow{2}{*}{ Technique used in papers } & \multirow{2}{*}{$\begin{array}{l}\text { Based on } \\
\text { strategy } \\
\text { of MRS }\end{array}$} & \multirow{2}{*}{$\begin{array}{c}\text { Adaptation } \\
\text { system }\end{array}$} & \multicolumn{3}{|c|}{ Type of 3D model } & \multicolumn{2}{|c|}{ Type of system } & \multirow{2}{*}{$\begin{array}{l}\text { For improving } \\
\text { SVS or MRS? }\end{array}$} \\
\hline & & & & $\begin{array}{c}\text { Selected } \\
\text { randomly }\end{array}$ & $\begin{array}{l}\text { Course } \\
\text { models } \\
\end{array}$ & $\begin{array}{c}\text { Standard } \\
\text { models } \\
\end{array}$ & course & $\begin{array}{c}\text { Training } \\
\text { system }\end{array}$ & \\
\hline [16] & Software tutorials & & & & & & & & SVS \\
\hline$[18]$ & E-learning module & & & & & & & & SVS \\
\hline [19] & $\begin{array}{l}\text { eBook, multi-touch screen } \\
\text { technology }\end{array}$ & & & & & & & & SVS \\
\hline [21] & $\mathrm{VR}, \mathrm{AR}$, and PDF3D & & & & & & & & SVS \\
\hline [33], [34] & AR only & & & & & & & & SVS \\
\hline [35] & SketchUp with AR & & & & & & & & SVS \\
\hline$[7]$ & VR, Training website & & & & & & & & MRS \\
\hline [22] & Web 3D & & & & & & & & SVS \\
\hline [24] & Colored 3D & & & & & & & & SVS \\
\hline [17] & Flash Courseware & & & & & & & & SVS \\
\hline
\end{tabular}

\section{ADAPTATION SYSTEM FOR LEARNING}

Each learner has different abilities and skills in learning. Some of the learners get the information and understand it in short time based on its prior knowledge, abilities, and learning skills. On the other hand, some students learn with a long time to process the received information based on many factors such as age, prior knowledge, abilities, and learning skills.

According to that differentiation in getting and processing information, there is an electronic system can change according to the level of each learner. It can be adapted based on each student level of training and learning. The system is called Adaptive Hypermedia System (AHS) [40]. The AHS offers more attention for the individual learning [41].

The AHS is based on some Artificial Intelligence (AI) technologies [42].The AHS is an electronic system to support adaptive (dynamic) content for each learner [40]. The AHS used in the educational area to offer appropriate content and information for each student, allow each learner to train based on his level, increase the satisfaction of learner, and improve the efficiency (learn in a short time) and effectiveness (assessment results) of learning [43].

The AHS used on the web and in the educational area [44]. This system "build a model of the individual user and use it to adapt the content or/and the hyper-structure of the pages in a hypermedia environment" [45]. There are four categories of AHS. The categories are [46] (Adaptive Interaction, Adaptive Course Delivery, Content Discovery and Assembly, and Adaptive Collaboration Support).

There is only one category used in the educational area and allow the content (material) of the system to be changed for each learner. The category is (Adaptive Course Delivery) which use many techniques applied in learning and educational environments. The content adapted for each student based on the information and lever of each one. This category "intended to tailor a course (or, in some cases, a series of courses) to the individual learner." Adaptive Course Delivery used to adapt between contents of courses and student requirements or level [46]. Therefore, and based on the features of this category, we used it in building our system of training.

The AHS used in learning environments has three basic models. The models are domain model (DM), user (learner) model (UM), and adaptation model (AM) [40], [46], [45], [42].

Domain model (DM): the domain model (application model) is the course produced to the learner in AHS of elearning environments. The DM represent a description of how the content information is built and represent the relationship between the course elements (pages and information).

User model (UM): the UM represent the information of users such as result and levels of training, prior knowledge, goals, and navigation history of each learner. The UM updated based on the history of knowledge and navigation. DM represents the user (learner) knowledge and history of navigation. The UM represent the relation between the student and the DM by keeping track of navigation of the learner among the content of the system.

Adaptation model (AM): the AM represent what can be adapted, when and how it is adapted. The AM consists of adaptation rules to fit between content information and navigation of user. The AM used as a guide for the learner to navigate among the pages and links on the web. The adaptation is performed based on UM and DM by the adaptation rules 
which presented in AM. The AM consist a set of generic and specific rules. The general adaptation rules are used to represent variables that are concepts and concepts relationship. However, the specific adaptation rule is concert concepts (not variables) and must be defined by the author.

\section{GENDER DIFFERENCES}

There are differences in SVS especially MRS between females' and males' skills. Many researches by Li [12], [13], [14], [10], [15] concluded that males outperform females in a most of spatial tasks, particularly when they involve mental rotation tests. "Males tend to outperform women on spatial reasoning tests significantly. Differences have been attributed to a multitude of factors including biological, social and cultural, and educational factors and are believed to contribute to the fact that males outnumber females in science and mathematics fields" [15].

Another studies by Sorby [47], [48], [1], [49], [38] and studies by Yoon and Maeda [50], [51], [52], [2], [53] and [54] concluded that there is a gender significant difference in MRS and when they solve mental rotation tasks. Males outperform females on mental rotation tasks due to the differentiation in using mental rotation strategy that males using holistic strategy while females using analytical strategy. Other researchers [55], [56] conclude that the females SVS needed to be improved according to their strategy (analytical style ) to overcome the difference between them and males' score of MRS. That is, many of females tend to use their both hemispheres (combined style) and many of females using the left hemisphere (sequential style) that is an analytical strategy when they solve the mental rotation tests. The analytical strategy for mentally rotating a 3D object is based on rotating the object with step by step way and based on features of the object such as all three axes rotated with the object, colors, shapes, and sizes.

\section{Summary OF RoAd MAP FOR DESIGN BETTER SySTEM FOR TRAINING ON MRS}

We can summarize that the freshmen engineering students need to improve their SVS by many strategies and not only by using interactive 3D models. The guidelines to build a system training are the following:

- Training on mental rotation using VR technology to allow students to learn on models as it in reality.

- Using holistic strategy for training male gender and combined strategy for female gender is the most appropriate mental rotation strategies.

- Using adaptation systems to adjust the training exercises to fit the level of each student.

- Do training at the beginning of the semester to overcome the difficulties while studying engineering courses.

- The 3D models have to be standard models such as models produced by Purdue in PSVT.

- It is better to be target female gender because it has lower spatial abilities than males.

\section{CONCLUSION}

Engineering students need to have high MRS as it ensures the high SVS that enables students to pass and understand the engineering graphics courses. The freshmen students in engineering fields are facing difficulties to how to imagine any 3D model. The male outperforms females in MRS. So, the first-year students women engineering students need to enhance their spatial abilities.

In this paper, we illustrate the technique used to improve the SVS in general, and MRS mainly. We represented the previous studies tried to improve the SVS, and we represented the related strategies and method for that improving. A comparative study concluded for the solutions proposed for enhancing the spatial skills of engineering students.

A road map for improving the MRS for female engineering is finally presented based on the discussed solution. For the future work, we advise building system training enhancing the MRS for freshmen females' students. The training system must be gathering the advantages of previous solutions and based on the suggestions of road map design we can build a better system for training on MRS.

\section{REFERENCES}

[1] S. A. Sorby, "Developing 3-D spatial visualization skills," Engineering Design Graphics Journal, vol. 63, no. 2, 2009.

[2] Y. Maeda and S. Y. Yoon, “A meta-analysis on gender differences in mental rotation ability measured by the Purdue spatial visualization tests: Visualization of rotations (PSVT: R)," Educational Psychology Review, vol. 25, no. 1, pp. 69-94, 2013.

[3] G. J. Grant, "Impact of dynamic graphics on mental rotation of 3D objects with undergraduate students of varying levels of spatial ability," 2016.

[4] J. V. Ernst, D. Lane, and A. C. Clark, "Pictorial Visual Rotation Ability of Engineering Design Graphics Students," Engineering Design Graphics Journal, vol. 79, no. 1, pp. 1-13, 2015.

[5] E. S. Uria and M. G. Mugika, Methodology for Part Visualization Problem Solving-the Importance of the Process. INTECH Open Access Publisher, 2010.

[6] C. Özgen, "STRATEGIES AND DIFFICULTIES IN SOLVING SPATIAL VISUALIZATION PROBLEMS: A CASE STUDY WITH ADULTS," 2012.

[7] P. Cole, "Measuring the Effectiveness of Software-Based Training to Improve the Spatial Visualization Skills of Students in STEM Disciplines in Higher Education Institutions," 2016.

[8] J. A. Jimoh, "Comparative Effects of Two and Three Dimensional Techniques of Autocad on Spatial Ability, Interest and Achievement of National Diploma Students in Engineering Graphics," 2010.

[9] L. Daghestani, "The Design, Implementation and Evaluation of a Desktop Virtual Reality for Teaching Numeracy Concepts via Virtual Manipulatives," 2013.

[10] Y. Li, S. Wu, J. Zhu, and M. W. O’Boyle, "Sex and ability differences in neural activation for disembedding figures: An EEG investigation," Learning and Individual Differences, vol. 35, pp. 142-146, 2014.

[11] O. Blazhenkova and M. Kozhevnikov, "The new object-spatial-verbal cognitive style model: Theory and measurement," Applied cognitive psychology, vol. 23, no. 5, pp. 638-663, 2009.

[12] Y. Li and M. W. O’Boyle, "How sex, native language, and college major relate to the cognitive strategies used during 3-D mental rotation," The Psychological Record, vol. 58, no. 2, p. 287, 2008.

[13] Y. Li and M. W. O’Boyle, "Differences in mental rotation strategies for native speakers of Chinese and English and how they vary as a function of sex and college major," The Psychological Record, vol. 61, no. 1, p. $2,2011$. 
[14] Y. Li and M. O’Boyle, "How sex and college major relate to mental rotation accuracy and preferred strategy: an electroencephalographic (EEG) investigation," The Psychological Record, vol. 63, no. 1, p. 27, 2013.

[15] Y. Li and M. O’Boyle, "Mental Rotation Strategies Used by Males/Females and Physical/Social Science Majors: An EEG Study."

[16] I. Esparragoza, "Enhancing Visualization Skills in Freshman Engineering Students," in Proceedings from the 59th Annual Meeting and Conference of the ASEE Engineering Design Graphics Division, 2004, pp. 21-23.

[17] Li-hong Luo and T. Xia-mei, "A Method of Using Interactive 3D Element in Flash Courseware," in E-Learning, E-Business, Enterprise Information Systems, and E-Government, 2009. EEEE'09. International Conference on, 2009, pp. 65-67.

[18] M. N. Raol and V. Vaithyanathan, "Computer Aided Interactive Learning of Engineering Graphics-An E-Learning Module," in Computing, Communication and Networking, 2008. ICCCn 2008. International Conference on, 2008, pp. 1-4.

[19] J. de la Torre, J. L. Saorin, M. Contero, and J. Dorribo-Camba, "Interactive sketching in multi-touch digital books. A prototype for technical graphics," in Frontiers in Education Conference, 2013 IEEE, 2013, pp. 190-194.

[20] A. Rodriguez, B. Rey, M. Clemente, M. Wrzesien, and M. Alcañiz, "Assessing brain activations associated with emotional regulation during virtual reality mood induction procedures," Expert Systems with Applications, vol. 42, no. 3, pp. 1699-1709, 2015.

[21] M. G. Dominguez, J. Martin-Gutierrez, C. R. Gonzalez, and C. M. M. Corredeaguas, "Methodologies and tools to improve spatial ability," Procedia-Social and Behavioral Sciences, vol. 51, pp. 736-744, 2012.

[22] H. Olmedo, K. Olalde, and B. Garcia, "MotoStudent and the Web3D," Procedia Computer Science, vol. 75, pp. 84-94, 2015.

[23] N. A. A. Gonzalez, "How to Include Augmented Reality in Descriptive Geometry Teaching," Procedia Computer Science, vol. 75, pp. 250-256, 2015.

[24] J. Petros, M. Jones, M. R. Moustafa, and V. Jovanovic, "Application of Color on 3D Dynamic Visualizations for Engineering Technology Students and Effects on Spatial Visualization Ability: A QuasiExperimental Study," 2016

[25] J. Martin-Gutierrez, R. E. N. Trujillo, and M. M. Acosta-Gonzalez, "Augmented Reality Application Assistant for Spatial Ability Training. HMD vs Computer Screen Use Study," Procedia-Social and Behavioral Sciences, vol. 93, pp. 49-53, 2013.

[26] D. I. Miller and D. F. Halpern, "Can spatial training improve long-term outcomes for gifted STEM undergraduates?," Learning and Individual Differences, vol. 26, pp. 141-152, 2013.

[27] T. J. Branoff, "Spatial Visualization Measurement: A Modification of the Purdue Spatial Visualization Test-Visualization of Rotations.," Engineering Design Graphics Journal, vol. 64, no. 2, pp. 14-22, 2000.

[28] S. Islam, "Assessment of Spatial Visualization Skills in Freshman Seminar."

[29] M. Harle and M. Towns, "A review of spatial ability literature, its connection to chemistry, and implications for instruction," Journal of Chemical Education, vol. 88, no. 3, pp. 351-360, 2010.

[30] R. Guay, Purdue spatial visualization test. Purdue University, 1976.

[31] S. A. Sorby and N. Veurink, "Long-term Results from Spatial Skills Intervention among First-Year Engineering Students," in Proceedings of the 65th Midyear Meeting of the Engineering Design Graphics Division of ASEE, 2010.

[32] M. E. Smith, "The Correlation Between a Pre-Engineering Student's Spatial Ability and Achievement in an Elecetronics Fundamentals Course," All Graduate Theses and Dissertations, p. 254, 2009.

[33] R. Manseur, "Virtual reality in science and engineering education," in Frontiers in Education, 2005. FIE'05. Proceedings 35th Annual Conference, 2005, p. F2E-8.

[34] E. G. de Rave, F. Jimenez-Hornero, A. Ariza-Villaverde, and J. TaguasRuiz, "DiedricAR: a mobile augmented reality system designed for the ubiquitous descriptive geometry learning," Multimedia Tools and Applications, pp. 1-23, 2016.
[35] J. Martin Gutierrez, M. Contero, and M. Alcaniz, "Augmented reality to training spatial skills," Procedia Computer Science, vol. 77, pp. 33-39, 2015.

[36] S. A. Sorby, "Spatial abilities and their relationship to computer aided design instruction," age, vol. 4, p. 1, 1999.

[37] S. A. Sorby, "Developing 3D spatial skills for engineering students," Australasian Journal of Engineering Education, vol. 13, no. 1, pp. 1-11, 2007.

[38] M. A. Sadowski and S. A. Sorby, "A Delphi Study as a First Step in Developing a Concept Inventory for Engineering Graphics," in Engineering Design Graphics Division 66th MidYear Meeting Proceedings, 2012.

[39] T. Delahunty, S. Sorby, N. Seery, and L. Pérez, "Spatial Skills and Success in Engineering Education: A Case for Investigating Etiological Underpinnings," 2016.

[40] H. Wu, G.-J. Houben, and P. De Bra, "Supporting user adaptation in adaptive hypermedia applications," in Proceedings InfWet2000. Rotterdam, the Netherlands, 2000.

[41] Y. E. A. Mustafa and S. M. Sharif, "An approach to adaptive e-learning hypermedia system based on learning styles (AEHS-LS): Implementation and evaluation," International Journal of Library and Information Science, vol. 3, no. 1, pp. 15-28, 2011.

[42] S. Aammou, M. Khaldi, A. Ibrahimi, and K. El Kadiri, "Adaptive hypermedia systems for e-learning," in Education Engineering (EDUCON), 2010 IEEE, 2010, pp. 1799-1804.

[43] E. Popescu, "Dynamic adaptive hypermedia systems for e-learning," 2008.

[44] D. Barac, Z. Bogdanovic, A. Milic, B. Jovanic, and B. Radenkovic, "Developing adaptive e-learning portal in higher education," in ToulonVerona Conference" Excellence in Services," 2015.

[45] T. Tsandilas, "Adaptive Hypermedia and Hypertext Navigation," 2003.

[46] A. Paramythis and S. Loidl-Reisinger, "Adaptive learning environments and e-learning standards," in Second european conference on e-learning, 2003, vol. 1, no. 2003, pp. 369-379.

[47] S. A. Sorby, T. Drummer, K. Hungwe, and P. Charlesworth, "Developing 3-D spatial visualization skills for non-engineering students," in Proceedings of the 2005 American Society for Engineering Education Annual Conference I\& Exposition, 2005, vol. 10, pp. 1-10.

[48] S. A. Sorby, "Assessment of a' New and Improved' Course for the Development of 3-D Spatial Skills," Engineering Design Graphics Journal, vol. 69, no. 3, 2009.

[49] N. Veurink, A. Hamlin, J. Kampe, S. Sorby, D. Blasko, K. HollidayDarr, J. Trich Kremer, L. Abe Harris, P. Connolly, M. Sadowski, and others, "Enhancing Visualization Skills-Improving Options aNd Success (EnViSIONS) of Engineering and Technology Students," Engineering Design Graphics Journal, vol. 73, no. 2, 2009.

[50] S. Y. Yoon, "Psychometric Properties of the Revised Purdue Spatial Visualization Tests: Visualization of Rotations (The Revised PSVTR).," ProQuest LLC, 2011.

[51] A. C. Medina, H. B. Gerson, and S. A. Sorby, "Identifying Gender Differences in the 3-D Visualization Skills of Engineering Students in Brazil and in the United States.," 1998.

[52] Y. Maeda and S. Y. Yoon, "Measuring Spatial Ability of First-Year Engineering Students With the Revised PSVT: R," in American Society for Engineering Education, 2011.

[53] Y. Maeda and S. Y. Yoon, "Are Gender Differences in Spatial Ability Real or an Artifact? Evaluation of Measurement Invariance on the Revised PSVT: R," Journal of Psychoeducational Assessment, p. $0734282915609843,2015$.

[54] S. Y. Yoon and K.-H. Min, "College students' performance in an introductory atmospheric science course: associations with spatial ability," Meteorological Applications, vol. 23, no. 3, pp. 409-419, 2016.

[55] J. L. Mohler, "Examining the spatial ability phenomenon from the student's perspective," 2006.

[56] T. Tseng and M. Yang, "The role of spatial-visual skills in a projectbased engineering design course," 2011. 